\title{
The mediating role of self-efficacy in the relationship between Big five personality and depressive symptoms among Chinese unemployed population: a cross-sectional study
}

\author{
Yang Wang, Lutian Yao, Li Liu, Xiaoshi Yang, Hui Wu, Jiana Wang and Lie Wang*
}

\begin{abstract}
Background: Besides the rapid growth of economy, unemployment becomes a severe socio-economic problem in China. The huge population base in China makes the unemployed population a tremendously huge number. However, health status of unemployed population was ignored and few studies were conducted to describe the depressive symptoms of unemployed individuals in China. This study aims to examine the relationship between Big five personality and depressive symptoms and the mediating role of self-efficacy in this relationship.

Methods: This cross-sectional study was performed during the period of July to September 2011. Questionnaires consisting of the Center for Epidemiologic Studies Depression Scale (CES-D), the Big Five Inventory (BFI) and the General Self-efficacy Scale (GSE), as well as demographic factors, were used to collect information of unemployed population. A total of 1,832 individuals (effective response rate: 73.28\%) became our subjects. Hierarchical linear regression analyses were performed to explore the mediating role of self-efficacy.

Results: The prevalence of depressive symptoms was $67.7 \%$ among Chinese unemployed individuals. After adjusting for demographic characteristics, extraversion, agreeableness and conscientiousness were all negatively associated with depressive symptoms whereas neuroticism was positively associated with depressive symptoms. The proportion of mediating effect of self-efficacy in the relationship between extraversion/agreeableness/conscientiousness/neuroticism and depressive symptoms was $25.42 \%, 10.91 \%, 32.21 \%$ and $36.44 \%$, respectively. Self-efficacy is a mediator in the relationship between extraversion/agreeableness/conscientiousness/neuroticism and depressive symptoms.
\end{abstract}

Conclusion: Self-efficacy partially mediated the relationship between Big five personality and depressive symptoms among Chinese unemployed individuals. Interventions that focus on both individuals' personality and self-efficacy may be most successful to reduce depressive symptoms of unemployed individuals.

Keywords: Depressive symptoms, Big five personality, Self-efficacy, Unemployed

\section{Background}

Besides the rapid growth of economy, unemployment becomes a severe socio-economic problem in China. Giles et al. estimated that unemployment rate of urban permanent residents increased from $6.1 \%$ to $11.1 \%$ from January 1996 to September 2002 in China [1]. The huge population base in China makes the unemployed population a

\footnotetext{
* Correspondence: liewang@mail.cmu.edu.cn

Department of Social Medicine, School of Public Health, China Medical University, No. 92 Beier Road, Heping District, Shenyang, Liaoning 110001, People's Republic of China
}

tremendously huge number. However, few studies were conducted to describe the health status of unemployed population in China.

Previous researches have indicated that the loss of employment was one of the factors that has considerable influence on health status [2-4]. Unemployment was found to be associated with alcohol consumption, somatisation, suicidal ideation and symptoms of physical illness [5] and resulted in the destruction of self-efficacy, which have harmful effects on unemployed' health [6]. Studies have also demonstrated a positive correlation between employment and improved

\section{Biomed Central}


self-confidence, self-esteem, and happiness and people in secure employment [7] are reported to recover more quickly from illness than unemployed [8].

The relationship between unemployment and mental health has also been reported by a number of researches $[2,4,9]$. Unemployed people are very likely to experience psychological tension, mainly depression and anxiety, which negatively affects their health, their family's security, and society's stability in general [10]. Depression is more elevated among the long-term unemployed [11]. Krysia has indicated that longer durations of unemployment predicted higher levels of depressive symptoms among young adults in the U.S. [12].

Previous studies have indicated that personality was associated with depressive symptoms [13-15]. The Big five model is the most generally used dimensional model of personality. It includes five dimensions: extraversion (vs. introversion), agreeableness (vs. antagonism), conscientiousness (vs. lack of direction), neuroticism (vs. emotional stability) and openness (vs. closeness to experience). Extraversion was shown to be negatively associated with depression while neuroticism to be positively associated with depression [13]. Kotov et al. conducted a quantitative review to examine the associations between Big five personality and depression and found that depression groups score low on conscientiousness [14]. Bienvenu et al. found a positively association between openness of experience and depression [15]. However, little is known about these associations among unemployed population in China.

"Self-efficacy is the belief in one's capabilities to organize and execute the courses of action required to produce given attainments" [16]. Since self-efficacy was introduced by Bandura, studies examining the relationship between self-efficacy and depression have showed that those who scored higher on self-efficacy are less likely to develop depressive symptoms $[17,18]$. Self-efficacy is not a static characteristics, as elaborated by Bandura. Theoretically, internal personal factors and external environment both can alter one's self-efficacy. Self-efficacy is also reported as a positive resource for combating diseases such as diabetes [19], oncology [20] and osteoarthritis [21].

Although both the association between Big five personality and depressive symptoms and the association between self-efficacy and depressive symptoms have been confirmed by previous studies, the role of self-efficacy as a mediator between Big five and depressive symptoms has not been examined to our knowledge. A well-known theory in the field of stress is transactional theory proposed by Lazarus and Folkman in 1984 [22]. According to this theory, an individual's reaction to the stress is mediated by the subjective evaluation (i.e., appraisal) of the environment and the process of coping with a stressful event. Appraisals of situations and coping behavior are influenced by personal characteristics such as personality, perceived control, self-efficacy, and social skills. Based on this theory, we considered not only the possibility that Big five personality predicts depressive symptoms, but also the possibility that the effect of Big five personality on the depressive symptoms is mediated through the effect of Big five personality on self-efficacy.

With the purpose of relieving the adverse effects of unemployment and enhancing unemployed' health status, we conducted a cross-sectional survey among unemployed population to explore the relation of Big five personality and self-efficacy to depressive symptoms. There are three specific aims in the present study. First, to investigate the prevalence of depressive symptoms among unemployed individuals in China. Second, to examine the relation of Big five personality and selfefficacy to depressive symptoms among unemployed population in China. Third, to explore the mediating role of self-efficacy in the relationship between Big five personality and depressive symptoms among unemployed population in China.

\section{Method}

\section{Procedure and sampling}

A cross-sectional study was conducted in Mainland, China, from January to September 2011. Based on the geographic and administrative divisions of Mainland, China, all provinces and municipalities are divided into three regions: East regions, Central regions and West regions. Four provinces in each region were randomly selected (in Central regions, three provinces, along with the municipality of Beijing were selected). Two cities were randomly selected from each province. A total of 22 cities and 1 municipality were selected. Then, in each sampled city or municipality, unemployed people, aged 18 to 65 years old, who are jobless and have been actively looking for work within the past four weeks and registered in the labor markets of the local Human resources and Social Security Bureau, were enrolled in this study by convenience sampling in the local large labor markets (at least 300 Unemployed individuals were registered). Eventually, 2,500 unemployed participants were recruited in this study and a pool of 1,832 unemployed participants (effective response rate: 73.28\%) constituted the potential study sample. After obtaining written informed consent to conduct this survey, the unemployed participants were interviewed face-to-face by trained interviewers from China Medical University. This study received ethics approval from the Committee on Human Experimentation of China Medical University.

Interviewers were enrolled voluntarily from the 4th year undergraduate students of China Medical University. A 2-day interviewer training was conducted by 
experts from School of Public Health, China Medical University. Sources of survey error, the role of interviewer in reducing error, interview techniques including standardized question asking, questionnaire format and conventions, clarification, feedback, answer recording, etc. were introduced to interviewers.

\section{Demographic characteristics}

Gender, age, education, martial status, chronic disease, household monthly income and duration of unemployment were obtained in this study. "Education" was categorized as "middle school or under", "senior high school" and "college or above". "Marital status" was categorized as "single", "married/cohabitation" and "divorced/separated/ widow". "Chronic disease" was defined as 'yes' if any of these chronic disease (e.g., hypertension, cardiovascular disease, diabetes, ulcer, chronic kidney disease, back pain and arthritis) had ever been diagnosed. Household monthly income was categorized as " $\leq 1000 \mathrm{rmb}(\approx 158$ dollars)", "1001 2000rmb" and ">2000rmb). Duration of unemployment was categorized as "1-2 months", "3-5 months", "6-11 months" and " $\geq 12$ months".

\section{Measurement of depressive symptoms}

Depressive symptoms were measured by the Center for Epidemiologic Studies Depression Scale (CES-D) [23]. It consisted of 20 items and each item was scored on a 4point Likert scale on the basis of frequency of occurrences of current depressive symptoms during the past week. Each item had four response categories ranging from 'rarely or none of the time' ( 0 points) to 'most or all of the times' (3 points), with the total score ranging from 0 to 60 . Higher score indicated higher level of depressive symptoms. Subjects scored of 16 or more were defined as "depressive symptoms" group [24].

The Chinese version of the CES-D has been used widely in Chinese population and demonstrated satisfactory reliability and validity $[25,26]$. In the present study, the Cronbach's alpha for the total scale was 0.884 .

\section{Measurement of big five personality}

Big five personality was measured by The Big Five Inventory (BFI), which was constructed by John, Donahue and Kentlein in 1991 [27,28]. It measured an individual on the Big Five Factors (dimensions) of personality which included extraversion (vs. introversion), agreeableness (vs. antagonism), conscientiousness (vs. lack of direction), neuroticism (vs. emotional stability) and openness (vs. closeness to experience). The inventory consisted of 44 items, and the extraversion dimension was measured by 8 items, the agreeableness dimension was measured by 9 items, the conscientiousness was measured by 9 items, the neuroticism dimension was measured by 8 items and the openness dimension was measured by 10 items. Each of the items is scored on a Likert scale from 1(strongly disagree) to 5 (strongly agree).

The Chinese version of the BFI has been used in Chinese population and demonstrated good reliability and validity $[29,30]$. In the present study, the Cronbach's alpha coefficients of extraversion, agreeableness, conscientiousness, neuroticism and openness were $0.723,0.759,0.786,0.753$ and 0.714 , respectively.

\section{Measurement of self-efficacy}

Self-efficacy was measured by General Self-efficacy Scale (GSE), developed by Schwarzer [31]. The Chinese version of this scale showed good reliability and validity when used in Chinese population [32,33]. The scale consisted of 10 items and each item was scored on a 4-point Likert scale from 1 (strongly disagree) to 4(strongly agree). Responses for all items were summed up to get an overall score and higher scores indicated higher level of selfefficacy. In the present study, the Cronbach's alpha for the total scale was 0.756 .

\section{Statistical analysis}

All analyses were conducted using SPSS 17.0 for Windows. Pearson's correlation coefficient was used to preliminarily examine the correlations among depressive symptoms, big five and self-efficacy.

Hierarchical multiple regression (HMR) analysis was performed to test the incremental variance of any given set of independent variables and to examine the mediating role of self-efficacy. Scores of depressive symptoms were used as dependent variables. The independent variables were entered in three steps. In step 1, all demographic variables were entered as control variables. Because marital status and educational level are categorical variables without a linear trend, we set dummy variables for the two variables respectively. For marital status, "married" was set as the reference group. For educational level, "middle school or under" was set as the reference group; in step 2, dimensions of Big five personality were added; in step 3, self-efficacy was added. The analysis was performed in stages by successively inputting several blocks of independent variables in the model. All statistical tests were twosided $(\alpha=0.05)$.

Baron and Kenny's analysis technique [34] was used for testing the hypothesis concerning the mediating effect of self-efficacy in the relationship between the dimensions of big five personality and depressive symptoms. According to Baron and Kenny, the following are the conditions for establishing mediation: (1) the independent variable (Big five personality) is significantly related with the dependent variable (depressive symptoms); (2) the independent variable (Big five personality) is significantly related with the mediator (self-efficacy); and (3) the mediator (self-efficacy) is significantly related with the dependent variable 
(depressive symptoms), with the effect of the independent variable (Big five personality) on the dependent variable (depressive symptoms) shrinking (partial mediator) or becoming statistically insignificant (full mediator) upon the addition of the mediator (self-efficacy) to the model.

All the continuous variables were standardized in order to avoid multicollinearity [35] before performing the regression analyses.

In addition, bootstrapping method was performed to confirm the mediation effect. Bootstrapping is an increasingly popular non-parametric method of testing mediation effect [36]. It involves repeatedly sampling from the data set and estimates the indirect effect in each resampled data set. It provides a powerful and reasonable method of obtaining confidence interval (CI) for mediation effect under most conditions. For each independent variable, when the bias-corrected and accelerated 95\% CI (BCa 95\% CI) of medication effect (a*b product) excluded 0 , it indicated that the mediating role of self-efficacy was statistically significant. To estimate the degree to which the effect of Big five personality on depressive symptoms is mediated through self-efficacy, we also calculated the proportion of the indirect effect of Big five personality on depressive symptoms to the total effect. The bootstrap estimate presented in our study was based upon 5,000 bootstrap samples.

\section{Results}

Demographic characteristics of studied population and prevalence of depressive symptoms

Demographic characteristics of the subjects and the distributions of depressive symptoms in categorical variables are shown in Table 1 . The mean age of studied population was 34.88 years old $(\mathrm{SD}=10.59)$ and $56.1 \%$ of studied population were males. The mean score of depressive symptoms among the unemployed population in the present study was 21.39 and the prevalence of depressive symptoms was $67.7 \%$.

\section{Correlations among Big five personality, self-efficacy and depressive symptoms}

As seen in Table 2, extraversion, agreeableness, conscientiousness and openness were all negatively related with depressive symptoms whereas neuroticism was positively related with depressive symptoms. Therefore, the first condition of Baron and Kenny's technique to test the mediating role of self-efficacy was satisfied in the present study. Results in Table 2 also showed that extraversion, agreeableness, conscientiousness and openness were all positively related with self-efficacy whereas neuroticism was positively related with it. Thus, the second condition of Baron and Kenny's technique was also met.
Table 1 Demographic characteristics of study subjects and the distributions of depressive symptoms in categorical variables

\begin{tabular}{|c|c|c|}
\hline Variable & $N(\%)$ & $\begin{array}{l}\text { Depressive symptoms } \\
\text { Mean (SD) }\end{array}$ \\
\hline \multicolumn{3}{|l|}{ Gender } \\
\hline Males & 1027(56.1\%) & $21.62(10.81)$ \\
\hline Females & $805(43.9 \%)$ & $21.10(10.23)$ \\
\hline \multicolumn{3}{|l|}{ Age (yr) } \\
\hline$\leq 30$ & $778(42.5 \%)$ & $20.30(10.04)$ \\
\hline $31-40$ & $458(25.0 \%)$ & $22.21(10.57)$ \\
\hline$>40$ & $596(32.5 \%)$ & $22.19(11.08)$ \\
\hline \multicolumn{3}{|l|}{ Education } \\
\hline Middle school or under & $597(32.6 \%)$ & 23.69(11.68) \\
\hline Senior high school & $567(30.9 \%)$ & 21.03(10.06) \\
\hline College or above & $668(36.5 \%)$ & $20.10(9.67)$ \\
\hline \multicolumn{3}{|l|}{ Marital status } \\
\hline Single & $593(32.4 \%)$ & $20.01(9.87)$ \\
\hline Married/cohabitation & 1076(58.7\%) & $21.58(10.91)$ \\
\hline Divorced/ separated / widow & 163(8.9\%) & $25.20(9.58)$ \\
\hline \multicolumn{3}{|l|}{ Chronic disease } \\
\hline Yes & $834(45.5 \%)$ & $23.27(10.34)$ \\
\hline No & $998(54.5 \%)$ & 19.85(10.51) \\
\hline \multicolumn{3}{|l|}{ Household monthly income } \\
\hline$\leq 1000 \mathrm{rmb}$ & $421(23.0 \%)$ & $24.80(11.76)$ \\
\hline $1001 \sim 2000 \mathrm{rmb}$ & $815(44.5 \%)$ & $21.44(9.38)$ \\
\hline$>2000 \mathrm{rmb}$ & $597(32.6 \%)$ & 18.94(10.54) \\
\hline \multicolumn{3}{|l|}{ Duration of unemployment } \\
\hline $1-2$ months & $386(20.1 \%)$ & 18.33(9.86) \\
\hline 3-5 months & $372(20.3 \%)$ & $21.40(9.52)$ \\
\hline 6-11 months & $454(24.8 \%)$ & $22.47(10.01)$ \\
\hline$\geq 12$ months & $620(33.8 \%)$ & $22.59(11.69)$ \\
\hline
\end{tabular}

\section{Association between Big five personality and depressive symptoms}

Results of the hierarchical multiple regression models of depressive symptoms were presented in Table 3. Each block of the independent variables made a significant contribution to the variance of depressive symptoms. Big five personality explained $24.7 \%$ of the variance in the depressive symptoms while demographic characteristics including gender, age, marital status, education, chronic disease, household monthly income and duration of unemployment contributed $8.7 \%$ of the variance. After controlling for demographic characteristics, extraversion $(\beta=-0.111$, $\mathrm{P}<0.001)$, agreeableness $(\beta=-0.219, \mathrm{P}<0.001)$, conscientiousness $(\beta=-0.099, \mathrm{P}<0.001)$ were positively associated with depressive symptoms whereas neuroticism $(\beta=0.280, P<0.001)$ was negatively associated with it. 
Table 2 Means, standard deviations (SD) and correlations of continuous variables

\begin{tabular}{|c|c|c|c|c|c|c|c|c|}
\hline Variables & Mean & SD & 1 & 2 & 3 & 4 & 5 & 6 \\
\hline 1. Depressive symptoms & 21.39 & 10.56 & & & & & & \\
\hline 2. Extraversion & 25.94 & 4.13 & $-0.291^{* *}$ & & & & & \\
\hline 3. Agreeableness & 31.93 & 4.82 & $-0.415^{* *}$ & $0.244^{* *}$ & & & & \\
\hline 4. Conscientiousness & 30.74 & 4.75 & $-0.349^{* *}$ & $0.316^{* *}$ & $0.516^{* *}$ & & & \\
\hline 5. Neuroticism & 24.24 & 4.25 & $0.435^{* *}$ & $-0.319^{* *}$ & $-0.327^{* *}$ & $-0.341^{*}$ & & \\
\hline 6. Openness & 31.94 & 5.21 & $-0.211^{* *}$ & $0.347^{* *}$ & $0.370^{* *}$ & $0.398^{* *}$ & $-0.131^{* *}$ & \\
\hline 7. Self-efficacy & 38.29 & 5.69 & $-0.494^{* *}$ & $0.356^{* *}$ & $0.377^{* *}$ & $0.395^{* *}$ & $-0.516^{* *}$ & $0.335^{* *}$ \\
\hline
\end{tabular}

*P $<0.05$.

${ }^{* *} \mathrm{P}<0.01$ (two-tailed).

\section{Association between self-efficacy and depressive symptom}

The effect of self-efficacy on depressive symptoms was negative and significant $(\beta=-0.264, \mathrm{P}<0.001)$, accounting for an additional $4.3 \%$ of the variance of depressive symptoms.

The mediating role of self-efficacy in the relationship between Big five personality and depressive symptoms After adding self-efficacy in the regression model, the regression coefficients (absolute value of regression coefficient when it is negative) for extraversion (from $\beta=-0.111$ to $\beta=-0.083, \mathrm{P}<0.001$ ), agreeableness (from $\beta=-0.219$ to $\beta=-0.195, P<0.001$ ), conscientiousness (from $\beta=-0.099$ to $\beta=-0.067, P<0.001$ ) and neuroticism (from $\beta=0.178$, $\mathrm{P}<0.001$ ) all diminished as shown in the final model. Based on the third condition of Baron and Kenny's technique, we can see that self-efficacy is a partially mediator in the relationship between extraversion/agreeableness/conscientiousness/neuroticism and depressive symptoms.

Results of bootstrapping method showed that path coefficients of indirect effects ( $\mathrm{a}$ *b product) of extraversion/ agreeableness/conscientiousness/neuroticism on depressive symptoms through self-efficacy were -0.029 (BCa 95\% CI: $-0.044,-0.017$ ), -0.024 (BCa 95\% CI: -0.039 ,$0.011),-0.032$ (BCa 95\% CI: -0.049,-0.018), 0.103 (BCa 95\% CI: $0.080,0.128)$, respectively. The proportion of indirect effect to total effect of extraversion/agreeableness/conscientiousness/neuroticism was $25.42 \%, 10.91 \%$, $32.21 \%$ and $36.44 \%$, respectively. The mediating effect of self-efficacy in the relationship between neuroticism and depressive symptoms was the strongest.

\section{Discussion}

This study investigated the prevalence of depressive symptoms among Chinese unemployed population, explored the relationship between Big five personality and depressive symptoms and the mediating role of selfefficacy in this relationship. In this research, we found that $67.7 \%$ of Chinese unemployed individuals had depressive symptoms. This prevalence was almost two times higher than that was found in general populations in Japan [37] and Korea [38] and also higher than the prevalence for depressive disorders in the older, longterm unemployed population (38.5\%) in German [39].

In the present study, results of the last model of HMR indicated that extraversion, agreeableness and conscientiousness were all negatively associated with depressive symptoms whereas neuroticism was positively associated with depressive symptoms among Chinese employed population, when adjusting for demographic characteristics

Table 3 Hierarchical linear regression analysis results

\begin{tabular}{|c|c|c|c|}
\hline \multirow[t]{2}{*}{ Variables } & \multicolumn{3}{|c|}{ Depressive symptoms } \\
\hline & step $1(\beta)$ & step $2(\beta)$ & step $3(\beta)$ \\
\hline \multicolumn{4}{|l|}{ Block 1} \\
\hline Gender & $-0.026^{*}$ & -0.018 & -0.026 \\
\hline Age & -0.077 & 0.009 & 0.007 \\
\hline Dummy_m1 & -0.041 & -0.040 & -0.025 \\
\hline Dummy_m2 & $0.103^{* *}$ & $0.046^{*}$ & $0.042^{*}$ \\
\hline Dummy_e1 & $-0.068^{*}$ & -0.036 & -0.026 \\
\hline Dummy_e2 & $-0.074^{*}$ & -0.039 & -0.029 \\
\hline Chronic Disease & $0.113^{* *}$ & $0.059^{* *}$ & $0.061^{* *}$ \\
\hline Household monthly income & $-0.172^{* *}$ & $-0.124^{* *}$ & $-0.107^{* *}$ \\
\hline Duration of unemployment & $0.085^{* *}$ & $0.063^{* *}$ & $0.060^{* *}$ \\
\hline \multicolumn{4}{|l|}{ Block 2} \\
\hline Extraversion & & $-0.111^{* *}$ & $-0.083^{* *}$ \\
\hline Agreeableness & & $-0.219^{* *}$ & $-0.195^{* *}$ \\
\hline Conscientiousness & & $-0.099^{* *}$ & $-0.067^{* *}$ \\
\hline Neuroticism & & $0.280^{* *}$ & $0.178^{* *}$ \\
\hline Openness & & 0.020 & $0.060^{* *}$ \\
\hline \multicolumn{4}{|l|}{ Block 3} \\
\hline Self-efficacy & & & $-0.264^{* *}$ \\
\hline $\mathrm{R}^{2}$ & 0.087 & 0.334 & 0.377 \\
\hline$\Delta R^{2}$ & 0.087 & 0.247 & 0.043 \\
\hline
\end{tabular}

${ }^{*} \mathrm{P}<0.05$ ** $\mathrm{P}<0.01$ (two-tailed).

Dummy_m1 means "Single" vs. "Married/Cohabitation", Dummy_m2 means

"Divorced/Widow/Separated" vs. "Married/Cohabitation";

Dummy_e1 means "Senior high school" vs. "Middle school or under",

Dummy_e2 means "College or above" vs. "Middle school or under". 
and self-efficacy. The association between openness and depressive symptoms was initially non-significant, but became positively significant when self-efficacy was included in the model. Of the Big five personality, neuroticism and extraversion are the two major dispositions reflecting individual differences in the degree to which one experiences overall negative and positive affect, respectively. Individuals who score high on neuroticism are more self-conscious and more prone to feelings of inadequacy, worry and nervousness [14]. Compared to individuals with lower scores on neuroticism, they are more likely to experience negative emotions such as angry, anxiety, helplessness, fearfulness and depression [13]. McCann reported that neuroticism even accounted for $32.0 \%$ of the variance in suicide rates when demographics and depression were controlled [40]. The strong relationship between neuroticism levels and stress might due to a highly inability of individuals with higher scores on neuroticism to cope effectively with stressors, which would increase the amount of stress [13]. In contrast, extraversion seems to encompass sociability, enthusiasm, cheerfulness and reports of subjective wellbeing [41]. Highly extraverted individuals would suffer less under stress, as they would appraise stressful events as challenges and they see situations as opportunities for reward, not for punishment [39]. Researches have revealed that extraverted individuals reported less perceived stress and depression $[42,43]$.

Results of the present study showed that self-efficacy played a positive role in alleviating depressive symptoms. This was in agreement with conclusions from previous studies that efforts to establish and maintain a sense of control over one's life and environment might serve to modify the appraisal of stressful circumstances and to build a certain degree of resistance to depressive symptoms $[17,44]$. A strong sense of self-efficacy enhances personal accomplishments, reduces stress and lowers vulnerability to depression. In contrast, individuals with low self-efficacy doubt their capacities and have low aspirations and weak commitment to the goals they choose to pursue [45]. They are more vulnerable to stress and depression $[16,17,46]$. Self-efficacy development has been paid much attention among adolescences and patients $[45,47]$, however, programs targeted toward developing unemployed population' self-efficacy are few. To our knowledge, no self-efficacy interventions designed for unemployed have been conducted yet in China.

Big five personality not only had direct effect on depressive symptoms, but also had indirect effect on depressive symptoms through self-efficacy. In the present study, self-efficacy was found to partially mediate the relationship between extraversion/agreeableness/conscientiousness/neuroticism and depressive symptoms. Unemployed individuals who have higher scores on extraverted/agreeable/conscientious may have high selfefficacy, which in turn would lead to lower levels of depressive symptoms. And unemployed individuals who have higher scores on neuroticism may have low selfefficacy, which in turn would lead to higher levels of depressive symptoms. These findings suggested that interventions that focus on both individuals' personality and self-efficacy may be most successful to reduce depressive symptoms of unemployed individuals. A shift in stress and health research now called for is from managing health risks to developing individuals' strength and resilience. It is possible to modify responses of individuals who have higher scores on neuroticism through increasing awareness toward maladaptive ones and training coping selfefficacy. For example, cognitive-behavioral therapies and hardiness training have been shown to be effective in enhancing adaptive types of coping, perceptions of social support and attenuating psychological distress [48]. Administrators in different levels of Human resources and Social Security Bureau or organizations of social protection should pay attention to the development of such trainings.

Several strengths were presented in this study. Firstly, a wide coverage of 94 cities and 1 municipality in China and the large sample size endowed this study a great value to examine the relationships of Big five personality, self-efficacy and depressive symptoms among Chinese unemployed individuals. Secondly, face-to-face interviews provided a high response rate of this study and guaranteed the accuracy of the information. However, due to the cross-sectional design of this study, all findings obtained in the present study need to be confirmed in future prospective studies. And we only focused on the associations of Big five personality and self-efficacy with depressive symptoms, other protective mechanisms in addition to those studied here that are important to consider in the experience of depressive symptoms were not included.

\section{Conclusions}

There was a high prevalence of depressive symptoms among Chinese unemployed population. After adjusting for demographic characteristics, extraversion, agreeableness and conscientiousness were all negatively associated with depressive symptoms whereas neuroticism was positively associated with depressive symptoms. In the present study, self-efficacy was found to partially mediate the relationship between extraversion/agreeableness/ conscientiousness/neuroticism and depressive symptoms. Unemployed individuals who are highly extraverted/agreeable/conscientious may have high self-efficacy, which in turn would lead to lower levels of depressive symptoms. And unemployed individuals who had higher scores on neuroticism may have low self-efficacy, which in turn 
would lead to higher levels of depressive symptoms. These findings suggested that interventions that focus on both individuals' personality and self-efficacy may be most successful to reduce depressive symptoms of unemployed individuals.

\section{Competing interests}

The authors declare that they have no competing interest.

\section{Authors' contributions}

YW was involved in all aspects of the paper including design of the study, questionnaire survey, analysis and interpretation of data, drafting and revising the manuscript and approval of the final version. LTY, LL, XSY and JNW were all involved in questionnaire survey and draft of the manuscript. HW and LW made substantive intellectual contributions to the interpretation of data and draft of the manuscript. All authors have read and approved the final manuscript.

\section{Acknowledgements}

The authors would like to thank all the research assistants from China Medical University who participated in the survey and helped with data entry.

Received: 23 January 2013 Accepted: 26 February 2014

Published: 3 March 2014

\section{References}

1. Giles J, Park A, Zhang J: What is China's true unemployment rate? China Econ Rev 2005, 16:149-170.

2. McKee-Ryan FM, Song Z, Wanberg CR, Kinicki AJ: Psychological and physical well-being during unemployment: a meta-analytic study. J App / Psychol 2005, 90:53-76.

3. Paul Kl, Geithner E, Moser K: Latent deprivation among people who are employed, unemployed, or out of the labor force. J Psychol 2009, 143:477-491.

4. O'Campo P, Eaton WW, Muntaner C: Labor market experience, work organization, gender inequalities and health status: results from a prospective analysis of US employed women. Soc Sci Me 2004, 58:585-594.

5. Kessler RC, Turner JB, House JS: Intervening processes in the relationship between unemployment and health. Psychol Med 1987, 17:949-961.

6. Eden D, Aviram A: Self-efficacy training to speed reemployment: helping people to help themselves. J Appl Psychol 1993, 78:352-360.

7. Cai L, Kalb G: Health status and labour force participation: evidence from Australia. Health Econ 2006, 15:241-261.

8. Dorling D: Unemployment and Health. BMJ 2009, 338:b829.

9. Milner A, Spittal MJ, Page A, Lamontagne AD: The effect of leaving employment on mental health: testing 'adaptation' versus 'sensitisation' in a cohort of working-age Australians. Occup Environ Med. in press.

10. Walid MS, Zaytseva N: The relationship of unemployment and depression with history of spine surgery. Perm J 2011, 15:19-22.

11. Stankunas M, Kalediene R, Starkuviene S, Kapustinskiene V: Duration of unemployment and depression: a cross-sectional survey in Lithuania. BMC Public Health 2006, 6:174.

12. Krysia NM: The Influence of past unemployment duration on symptoms of depression among young women and men in the United States. Am J Public Health 1826-1832, 2009:99.

13. Mohamadi Hasel K, Besharat MA, Abdolhoseini A, Alaei Nasab S, Niknam S: Relationships of personality factors to perceived stress, depression, and oral lichen planus severity. Int J Behav Med 2013, 20:286-292.

14. Kotov R, Gamez W, Schmidt F, Watson D: Linking "big" personality traits to anxiety, depressive, and substance use disorders: a meta-analysis. Psychol Bull 2010, 136:768-821.

15. Bienvenu OJ, Nestadt G, Samuels JF, Costa PT, Howard WT, Eaton WW: Phobic, panic and major depressive disorders and the Five-factor model of personality. J Nerv Ment Dis 2001, 189:154-161. Bandura A: Self-efficacy: The exercise of control. New York: Freeman;1997.

16. Maciejewski PK, Prigerson HG, Mazure CM: Self-efficacy as a mediator between stressful life events and depressive symptoms. Differences based on history of prior depression. Br J Psychiatry 2000, 176:373-378.
17. Tahmassian K, Moghadam JN: Relationship between self-efficacy and symptoms of anxiety, depression, worry and social avoidance in a normal sample of students. Iran J Psychiatry Behav Sci 2011, 5:91-98.

18. van de Laar KE, van der Bijl JJ: Strategies enhancing self-efficacy in diabetes education: a review. Sch Inq Nurs Pract 2001, 154:235-248.

19. Lev EL: Bandura's theory of self-efficacy: applications to oncology. Sch Inq Nurs Pract 1997, 11:21-37.

20. Allegrante JP, Marks R: Self-efficacy in management of osteoarthritis. Rheum Dis Clin North Am 2003, 29:747-768.

21. Lazarus RS, Folkman S: Stress, Appraisal, And Coping. New York: Springer; 1984

22. Radloff LS: The CES-D scale: a self-report depression scale for research in the general population. Appl Psychol Measure 1977, 1:385-401.

23. Berkman LF, Berkman CS, Kasl S, Freeman DH Jr, Leo L, Ostfeld AM, Cornoni-Huntley J, Brody JA: Depressive symptoms in relation to physical health and functioning in the elderly. Am J Epidemiol 1986, 124:372-388.

24. Wang JN, Sun W, Chi TS, Wu H: Prevalence and associated factors of depressive symptoms among Chinese doctors: a cross-sectional survey. Int Arch Occup Environ Health 2010, 83:905-911.

25. Yang X, Wang L, He J, Ge C, Chang Y, Fu J, Wei J, Pattaramongkolar E, Zhou Y: Factors related to depressive symptoms among Chinese caregivers of cancer patients. Psychooncol 2012, 21:1063-1070.

26. John OP, Donahue EM, Kentle RL: The "Big Five" Inventory-Versions $4 a$ and 54. University of California, Berkeley: Institute of Personality and Social Research; 1997.

27. John OP, Srivastava S: The Big-Five Trait Taxonomy: History, Theoretical Perspectives. In Handbook And Research. Volume 2nd edition. Edited by Pervin LA, John OP. New York: Guilford Press; 1999:102-138.

28. Tong $L$, Zhou $C$ : The Influence of work-family conflict on job satisfaction and life satisfaction of employees: Big five personality as a moderator. Psychol Sci 2009, 3:604-606 (in Chinese).

29. Zhang $X$, Zheng $X$ : The relationship between Big five personality and subjective well-being of adolescent students. Psychol Dev Educ 2005, 2:98-103 (in Chinese).

30. Schwarzer R, Bäßler J, Kwiate P, Schröder K, Zhang JX: The assessment of optimistic self-beliefs: comparison of the German, Spanish, and Chinese versions of the general self-efficacy scale. Appl Psychol 1997, 46:69-88.

31. Wang CK, Liu Y: Correlations among General self - efficacy, trait anxiety, state anxiety and test anxiety. Chinese J Clin Psychol 2000, 8:229-230 (in (hinese).

32. Shen JL, Tang D: Use of General Self-Efficacy Scale(GSES) in Chinese aged people. Chinese J Clin Psychol 2004, 4:342-344 (in Chinese).

33. Baron RM, Kenny DA: The moderator-mediator variable distinction in social psychological research: conceptual, strategic, and statistical considerations. J Pers Soc Psychol 1986, 51:1173-1182.

34. Cohen J, Cohen P, West SG, Aiken LS: Applied Multiple Regression/Correlation Analysis For The Behavioral Sciences. Hillsdale: Lawrence Erlbaum Associates; 2003.

35. Preacher KJ, Hayes AF: Asymptotic and resampling strategies for assessing and comparing indirect effects in multiple mediator models. Behav Res Methods 2008, 40:879-891.

36. Kaneita Y, Ohida T, Uchiyama M, Takemura S, Kawahara K, Yokoyama E, Miyake T, Harano S, Suzuki K, Fujita T: The relationship between depression and sleep disturbances: a Japanese nationwide general population survey. J Clin Psychiatry 2006, 67:196-203.

37. Park SG, Min KB, Chang SJ, Kim HC, Min JY: Job stress and depressive symptoms among Korean employees: the effects of culture on work. Int Arch Occup Environ Health 2009, 82:397-405.

38. Liwowsky I, Kramer D, Mergl R, Bramesfeld A, Allgaier AK, Pöppel E, Hegerl $\mathrm{U}:$ Screening for depression in the older long-term unemployed. SoC Psych Psych Epide 2009, 44:622-627.

39. McCann SJ: Suicide, big five personality factors, and depression at the American state level. Arch Suicide Res 2010, 14:368-374.

40. Mak AS, Blewitt K, Heaven PC: Gender and personality influences in adolescent threat and challenge appraisals and depressive symptoms. Pers Indiv Differ 2004, 36:1483-1496.

41. Ebstrup JF, Eplov LF, Pisinger C, Jørgensen T: Association between the Five Factor personality traits and perceived stress: is the effect mediated by general self-efficacy? Anxiety Stress Coping 2011, 24:407-419.

42. Grav S, Stordal E, Romild UK, Hellzen O: The relationship among neuroticism, extraversion, and depression in the HUNT Study: in relation to age and gender. Issues Ment Health Nurs 2012, 33:777-785. 
43. Nuttman-Shwartz O, Gadot L: Social factors and mental health symptoms among women who have experienced involuntary job loss. Anxiety Stress Coping 2012, 25:275-290.

44. Gordon MS, Tonge B, Melvin GA: The Self-Efficacy Questionnaire for Depressed Adolescents: a measure to predict the course of depression in depressed youth. Aust N Z J Psychiatry 2012, 46:47-54.

45. Steca P, Greco A, Monzani D, Politi A, Gestra R, Ferrari G, Malfatto G, Parati G: How does illness severity influence depression, health satisfaction and life satisfaction in patients with cardiovascular disease? The mediating role of illness perception and self-efficacy beliefs. Psychol Health 2013, 28:765-783.

46. Aliasgharpour M, Shomali M, Moghaddam MZ, Faghihzadeh S: Effect of a self-efficacy promotion training programme on the body weight changes in patients undergoing haemodialysis. J Ren Care 2012, 38:155-161.

47. Maddi SR, Khoshaba DM, Jensen K, Carter E, Lu JL, Harvey RH: Hardiness training for high-risk undergraduates. Nat Acad Advis Assoc J 2002, 22:45-55.

48. Maddi SR, Kahn S, Maddi KL: The effectiveness of hardiness training. Consult Psychol J 1998, 50:78-86.

doi:10.1186/1471-244X-14-61

Cite this article as: Wang et al:: The mediating role of self-efficacy in the relationship between Big five personality and depressive symptoms among Chinese unemployed population: a cross-sectional study. BMC Psychiatry 2014 14:61

\section{Submit your next manuscript to BioMed Central and take full advantage of:}

- Convenient online submission

- Thorough peer review

- No space constraints or color figure charges

- Immediate publication on acceptance

- Inclusion in PubMed, CAS, Scopus and Google Scholar

- Research which is freely available for redistribution 